\title{
Collective violence and construction of peace culture in the Basque Country: two experiences of memory, recognition and forgiveness
}

\author{
Violencia colectiva y construcción de cultura de paz \\ en el País Vasco:
}

dos experiencias de memoria, reconocimiento y perdón

\author{
Nekane Basabe \\ University of the Basque Country \\ nekane.basabe@ehu.eus \\ Miren Harizmendi \\ mharizmendi@bakeola.org \\ José J. Pizarro \\ University of the Basque Country \\ jose.pizarro@ehu.eus \\ Saioa Telletxea \\ University of the Basque Country \\ saioa.telletxea@ehu.eus \\ Pablo Castro \\ University of the Basque Country \\ pabloenrique.castro@ehu.eus \\ Sonia Padoan \\ University of the Basque Country \\ sonia.padoan@ehu.eus
}

University of the Basque Country / Bakeola, Fundación EDE

Citation/Cómo citar: Basabe, Nekane, Harizmendi, Miren; Pizarro, José J.; Telletxea, Saioa; Castro, Pablo; Padoan, Sonia. 2021. "Collective violence and construction of peace culture in the Basque Country: two experiences of memory, recognition and forgiveness». Deusto Journal of Human Rights, No. 8: 103-130. doi: http://dx.doi.org/10.18543/djhr.2286. 
Summary: Introduction. 1. Collective violence in Post-Conflict contexts: the case of the Basque Country. 2. Forgiveness in the context of intergroup conflict: Intergroup forgiveness. 3. Study 1. 3.1. Method. 3.1.1. Participants. 3.1.2. Procedure. 3.1.3. Measures. 3.1.4. Data analysis. 3.2. Results. 3.2.1. Means comparisons between groups pre and post intervention. 3.2.2. Empathy towards perpetrators and victims. 3.2.3. Self-transcendent emotions and negative emotions. 3.2.4. Mediation effects on intergroup forgiveness through selftranscendent emotions and empathy. 3.3. Conclusions. 4. Study 2. 4.1. Method. 4.1.1. Participants. 4.1.2. Procedure. 4.1.3. Measures. 4.2. Results. 4.3. Conclusions. 5. Discussion. References.

Abstract: Post-conflict societies must confront the past and build a culture of peace. Two interventions are presented here in the context of the Basque Country after the cessation of violence. The first, an intervention with the participation of victims of terrorism, where participants $\left(N=280 M_{\text {age }}=19.83\right.$ $S D=1.29)$ were assigned to intervention and control groups. Results showed that participation in the programme produced more favourable attitudes towards intergroup forgiveness, intergroup empathy, and the mediating effect of self-transcending emotions. Second, the Citizenship Processes programme of memory and recognition $\left(N=31 M_{\text {age }}=19.48 S D=3.91\right)$. Results showed an increase in forgiveness, intergroup empathy and a change in outgroup emotions from before to after the intervention. The impact of both programmes was medium-high and the relevance of combining narratives that avoid competitive victimisation and promote peaceful intergroup attitudes is discussed.

Keywords: Collective Violence, Peace Intervention, Intergroup Forgiveness, Empathy, Self-Transcendent Emotions.

Resumen: Las sociedades postconflicto deben hacer frente al pasado y construir una cultura de paz. Se presentan dos intervenciones en el contexto del País Vasco después del cese de la violencia. La primera, una intervención con la participación de víctimas del terrorismo, donde los participantes $\left(N=280 M_{\text {edad }}=19.83 D E=1.29\right)$ fueron asignados a grupos de intervención y control. Los resultados mostraron que la participación en el programa produjo actitudes más favorables hacia el perdón intergrupal, la empatía intergrupal, y el efecto mediador de las emociones auto-trascendentes. La segunda, el programa Procesos Ciudadanos de memoria y reconocimiento $\left(N=31 M_{\text {edad }}=19.48 D E=3.91\right)$. Los resultados mostraron un aumento en el perdón, la empatía intergrupal y un cambio en las emociones exogrupales de antes a después de la intervención. El impacto de ambos programas fue medio alto y se discute la relevancia de combinar las narrativas que eviten la victimización competitiva y promueva actitudes intergrupales pacíficas.

Palabras clave: Violencia colectiva, intervención para la Paz, perdón intergrupal, empatía, emociones transcendentes. 


\section{Introduction ${ }^{1}$}

In societies that have experienced intense events of collective violence (e.g. armed conflicts, wars, terrorist attacks, and other multiple acts of violence), different initiatives for social reconciliation have been encouraged, such as those based on respect and recognition of the victims. After a violent past, people from these contexts face the challenge of how to rebuild social bonds and restoring social trust between groups and individuals. Victims and perpetrators must confront the past, but also the society, as a whole must acknowledge the past and participate in building a culture of peace. In this line, several studies have shown that collective narratives that engage in intergroup violence emphasise the suffering of one's group and demand revenge, thus exacerbating conflict (Páez and Liu 2012). Conversely, when perceptions of ingroup victimisation decrease, the possibility of intergroup forgiveness increases (Shnabel Halabi and Noor 2013). Therefore, acknowledging the shared suffering of all conflict parties and mutual forgiveness can facilitate peaceful coexistence in contexts with groups in conflict (Salomon 2004; Vollhardt 2015). While this is indeed a challenging task, different interventions have been proposed centred on the recognition of victimisation, the inclusion of all groups and victims, the humanisation of the other through dialogue and contact, and the promotion of an attitude of mutual care and a hopeful vision for the future (Staub 2012; Wohl, Hornsey and Bennett 2012).

However, the general population's attitudes and emotions about the conflict - which are framed by the collective trauma due to sustained violence over long periods - often differ from the needs for forgiveness and reconciliation of the direct victims of the conflict (Martín-Beristain et al. 2010a), whose stories must be incorporated into the collective memory to acknowledge the recognition of the harm caused. It is, therefore, crucial to explore the impact of victims' testimonies on the general population as they play the role of making victims visible in their need to share their experiences and build collective memories; in addition, they can become tools for the recon-

1 Acknowledgements: The authors would like to thank the generous and courageous participation of the victim educators, as well as to all participants and the Bakeola organisation.

Funding. The Spanish Ministry of the Economy supported this research [under Grants PSI2017-84145-P/PID115738GB-100]; and Basque Government [under Grant IT1187-19] 
ciliation of fractured societies (Martín-Beristain and Páez 2000; MartínBeristain et al. 2010a).

This article explores the impact of different types of victim testimonies in the Basque Country, wherein in 2018 the terrorist group ETA announced its total disbandment after more than five decades of attacks.

\section{Collective violence in post-conflict contexts: The case of the Basque Country}

In 1996, World Health Organisation WHO defined three broad categories of violence: self-inflicted, interpersonal, and collective" (Krug et al. 2002, 1084). Collective violence consists of the instrumental use of violence by individuals organised in groups that violently attack others (i.e. both the general population as well as those from other groups) as a way of achieving certain political, economic or social objectives. It includes all aggressions and extortions resulting from war, terrorism, ethnic, religious or similar conflicts, gang and mafia organisations, and other organised collectives against other groups, civilian or military (Larizgoitia et al. 2011a). Regarding people who suffer from these forms of violence, a distinction can be made between "primary victims" (i.e. those who were the object of collective violence and first-degree relatives of people killed by acts of collective violence), and "secondary victims" (i.e. those who witnessed or learned about violent events from third parties).

The Basque Country is a politically autonomous region within Spain. Since the end of Franco's dictatorship and the establishment of democracy, various armed groups have emerged, being the most enduring the nationalist group ETA (originally formed as a political party in 1958), as well as other opposing groups (e.g. the Anti-Terrorist Liberation Group GAL, the Basque-Spanish Battalion [Batallón VascoEspañol, Triple A]). As a consequence of their activities, the Basque society suffered numerous violent actions. They included continuous threats against individuals and groups; assassinations and kidnappings; bomb attacks against people; demonstrations and street clashes, as well as cases of police torture. For the period 1960-2013, there are reported 3600 terrorist attacks and 836 deaths caused by ETA, 73 deaths associated with extreme right-wing and "counter-terrorism" groups and 5500 reports of police torture (Carmena et al. 2013; Gobierno de España 2011).

In October 2011, ETA declared the definitive cessation of its armed violence and in 2018 it announced its total dissolution, with a selective 
request for forgiveness that has not satisfied any of the associations and victims of terrorism. Since 2007, the autonomous government of the Basque Country (i.e. Eusko Jaurlaritza) has promoted various institutional initiatives for the recognition and memory of the victims of terrorism. Various pacifist entities, victims' organisations and civil society organisations have also developed initiatives for the recognition of the damage caused and the construction of culture of peace (Gobierno Vasco 2021a, Gobierno Vasco 2021b, Ruiz and Salazar, 2014).

As it could be expected, collective violence has also had a psychological and health impact. A study with victims in the Basque Country showed the effects on health and social relations many years after the trauma (Larizgoitia et al. 2011a, 2011b). In this report, several interviews were conducted with 36 primary victims -19 suffered the murder of a close relative, 10 survived attacks and other actions, 7 were subjected to repeated threats and extortionand a population-based survey $(N=2000)$. The study reported that the odds of perceiving worse physical and emotional health were 4 to 7 times higher among primary victims than among the general population; in addition, they perceived more loneliness and stigma and valued their social support and emotional climate more negatively (Larizgoitia et al. 2011b). While all forms of violence (e.g. physical, psychological) have had a significant effect and, at the same time, there has been an ongoing need to work for reconciliation, efforts that promote recognition of victims and a better co-existence are not always fruitful. Particularly, only a few studies have analysed attitudes towards forgiveness and reconciliation in the Basque Country. In one experiment, results indicated that people recognised the importance of forgiveness and reconciliation, yet trust in the institutional apologies offered was low. For this reason, the apologies reinforced support for victim reparation and perceptions of control, but they did not affect the attitudes towards forgiveness with perpetrators (Bobowik et al. 2010).

\section{Forgiveness in the context of intergroup conflict: Intergroup forgiveness}

Forgiveness, both interpersonal and intergroup, is a subject of great complexity. For a review of studies that have approached forgiveness from different philosophical, anthropological, clinical, developmental or social psychology perspectives, it is noticeable the work of Fehr 
et al. (2010). The specific case of intergroup forgiveness, however, has been relatively little studied because it is often understood that only those directly affected can participate (Mullet et al. 2011), and, when it comes to collective traumatic harm (such as the Holocaust or the genocide in Rwanda), it is perceived as an offence to the survivors (Staub and Perlman 2001, 197).

Nevertheless, an increasing number of studies have analysed mutual forgiveness as a facilitating factor for peaceful coexistence in contexts with groups in conflict (Páez et al. 2011; Salomon 2004; Staub and Pearlman, 2001; Vollhardt 2015). Intergroup Forgiveness (Noor et al. 2008 ) is conceived as a response to forgo negative emotions, thoughts and actions (e.g. intergroup revenge) in the face of the wrongdoing, and may entail clarity over each group's responsibility for the conflict, generosity in absolving the outgroup from the "total blame", and closure of the past hostile intergroup relationship (Bobowik et al. 2018).

A line of research has analysed the public rituals of institutional apologies for the violent past (Bobowik et al. 2019; Páez 2010) or the colonial past (Lastrego and Licata, 2010), supporting Gibson's (2004) original approach. In particular, that apologies will be effective when they help create historical narratives that capture the atrocities and suffering of all parties in conflict. In the same vein, a metaanalysis on interpersonal forgiveness (Fehr et al. 2010, 896) argued that "victims" prosocial motivational transformations occur via (a) mitigating cognitions regarding transgressions and their perpetrators, (b) positive (rather than negative) affect, and (c) relational and sociomoral constraints on forgiveness".

Regarding the facilitating and inhibiting factors of intergroup forgiveness, there is the meta-analytic review of Van Tongeren and colleagues (2014), which included 43 studies from 20 nationalities and diverse conflicts $-65 \%$ intra- and $35 \%$ inter-state. As a whole, this article considered nine types of factors, including those affective (i.e. empathy, negative emotions, collective guilt), positive cognitive (i.e. trust and amends), negative (i.e. perceived victimhood), and constraints (i.e. strong in-group identification, common, superordinate group identification, and intergroup contact), concluding that there was a moderate relationship between the affective, cognitive and constraining components with intergroup forgiveness. Pooled effect sizes were $r=0.37$ for empathy and $r=0.49$ for collective guilt, finding stronger effects for transgressions between countries (i.e. interstate transgressions) than within-countries (i.e. intrastate transgressions) (e.g. for empathy $r=0.55$ versus 0.31 ). The effect was larger for trust $(r=0.42)$ than for perceived victimisation $(r=-0.28)$ and was also 
moderated by type of offence, especially in the case of victimisation which ranged from $r=-0.45$ for interstate to $r=-0.23$ for intrastate offences. Finally, the effects were $r=-0.32$ for in-group identification, $r=0.29$ for common in-group identification, and $r=0.31$ for intergroup contact.

Among the correlates of intergroup forgiveness, there are emotions and affective states. Some examples include negative emotions towards outgroups (e.g. anger, rage) (Tam et al. 2007) and collective guilt (Wohl et al. 2012; Wohl and Branscombe 2005). Likewise, empathy has been associated with intergroup forgiveness in different socio-political contexts (Noor et al. 2008; Noor et al. 2015) and given the different perceptions of conflicting parties — which can affect individuals' emotional responses - perspective-taking is necessary for rapprochement between conflicting groups (Noor et al. 2008). In this vein, it can be argued that intergroup forgiveness is possible when individuals perceive and express other-oriented emotions (Van Tongeren et al. 2014), when negative outgroup-based emotions are inhibited or diminished (Tam et al. 2007; Wohl and Branscombe 2005; Wohl et al. 2012), and when reparation rituals express sadness or guilt (Rimé et al. 2011). In this vein, it has been recently proposed that Self-Transcendent Emotions (STEs) may play a positive role in the response to suffering and harm caused by collective violence. STEs include awe, (moral) elevation, gratitude, compassion, or feeling moved by love, and inspire moral models, focusing attention toward the needs and concerns of others while promoting a bonding with other people and social groups (Haidt 2003; Pizarro et al. 2021; Stellar et al. 2017; Van Cappellen and Rimé 2014).

Considering all of the above, we present two studies with two community interventions concerning the violent past in the Basque Country aimed at creating a culture of peace. The objective was to evaluate the use of humanizing narratives of victims, who take an active role in the social recognition of suffering and moral reparation, to contribute to social reconciliation (study 1 ), and to promote empathy and peace attitudes towards active participation in a process of encounter and dialogue (study 2).

These interventions incorporate inclusive narratives, which make visible the atrocities committed by terrorism, with an inclusive vision that considers the violence perpetrated by different groups in conflict. To this end, some of the previously reviewed correlates of intergroup forgiveness (e.g. such as empathy and outgroup emotions, both negative and positive) are considered. In addition, it is expected that the narratives of victim educators (see below) act as moral role models that inspire STEs and promote empathy and intergroup forgiveness. 


\section{Study 1}

This study analysed an intervention conducted in the Basque Country with a face-to-face intervention of different victims of collective violence, known as "victim-educators". The intervention —called Bakeaz Blai, a pedagogic program with victims as educatorsaimed at creating humanising narratives, thereby breaking away from competitive victimisation.

As a hypothesis, we expected that, in comparison with a condition where participants were exposed exclusively to statistical information about political violence in the Basque Country, participation in the intervention with victims as educators would increase the agreement with personal and intergroup forgiveness. These effects were expected to be present in all types of victims, including those who suffered from attacks perpetrated by ETA as well as those committed by State Security Forces and actions by para-police groups opposed to ETA (H1). Furthermore, we expected these effects to be mediated by two variables: STEs activated during the intervention and by empathy towards victims and perpetrators $(\mathrm{H} 2)$. In addition, we postulated a sequential mediation through increased STEs and thus increased empathy.

\subsection{Method}

\subsubsection{PARTICIPANTS}

Two hundred and eighty university students (69\% women, $M_{\text {age }}=19.89 S D=2.99$ ) participated in a quasi-experimental design. The participants were assigned into the control-information group (G0) $\left(N=55,71 \%\right.$ women, $\left.M_{\text {age }}=19.82 S D=1.27\right)$ and eight intervention groups $\left(N=225,70 \%\right.$ women, $\left.M_{\text {age }}=19.91 S D=3.28\right)$ that were composed by Social Work $(N=89)$ and Teacher Training students $(N=136)$ (four groups respectively).

No significant differences were found between intervention and control groups in terms of gender $\left[F_{(1,279)}=0.010, p=.921\right]$ or age $\left[F_{(1,279)}=0.038, p=.845\right]$. The prevalence of victimization in participants was $52 \%$ of people that knows someone close affected by political violence, and no significant difference were found between intervention and control groups $\left(\chi^{2}=1.437, p=.231\right)$. 


\subsubsection{Procedure}

The Bakeaz Blai programme was created and implemented during the period 2011-2012 with secondary school students, young people from leisure time groups, and teachers ( $N=130$ students and 6 teachers; and 8 leisure time groups $N=45$ people) (Ruiz and Salazar 2014). For this research, the intervention was adapted to the university context and designed to be scientifically evaluated, having been implemented in $2018 / 2019$. This corresponds to the first and only intervention directly involving victim-educators in the university setting. The initiative was the result of the first pilot experience between the organizing educational entity (i.e. Bakeaz Blai) and the university research team. Both parties agreed to be part of a systematic evaluation process and two faculties and a second-year course were selected, respectively. The interventions groups were exposed to the narratives with four different victims (3 men and 1 woman) of violence perpetrated by ETA, and State Security Forces. Victim educators fulfilled three conditions in their narratives: 1) they are above partisan struggle, 2) they defend the respect for the dignity and the right to life of all people, including perpetrators, and 3) they are advocates of promoting a culture of peace and social reconciliation (Ruiz and Salazar 2014). The victims advocate favourable attitudes towards peace and are members of various reconciliation and forgiveness initiatives in the Basque Country.

The intervention for all groups included two sessions, each lasting two hours. In the first, the groups - guided by two experts - aimed at reflection, awareness and sharing around concepts related to confrontation and political violence, such as conflict, hatred, forgiveness, the image of the enemy, stereotypes, human rights, etc. They were used to foster reflection and an exchange of ideas regarding concepts linked to confrontation and political violence. In the second session, during the first hour, the victims gave accounts of their personal experience as victims-survivors of political violence (i.e. victimisation) who support forgiveness and social reconciliation. In the second hour, a colloquium was organized where participants could share doubts and impressions with the invited person.

Interventions in all groups were standardised and guided by the same two experts to ensure homogenous implementation. Participants in the control-information group were exposed to an online presentation based only on statistical information about political violence in the Basque country. This presentation informed about the number of deaths and injured people in terrorist attacks, victims of torture and others, and all the information was extracted from reports 
of public institutions (Carmena et al. 2013; Gobierno España 2011). The questionnaires were completed before and after each intervention (one week after the intervention). All participants received information about the research project and signed an informed consent form. The research ethics committee of the university approved the intervention.

\subsubsection{MeAsures}

Forgiveness. Forgiveness was measured through four items adapted from the scale developed by Wohl and Branscombe (2005) to measure Intergroup Forgiveness (e.g. Victims need to forgive the harm caused to them by political violence; The victims must forgive those responsible for the political violence) (reliability was $\alpha=.833, .851$, for pre- and post-intervention measures), and Personal Forgiveness (e.g. I forgive those responsible for political violence; I can forgive actions of those who have caused harm) (reliability was $\alpha=.792, .895$, for both applications). The scale ranged from $1=$ Totally disagree to $7=$ Totally agree.

Intergroup empathy (adapted from Noor et al. 2008). We used 2 items measuring empathy towards perpetrators (e.g. When I think about those responsible for the violence, I understand that they may also have suffered and When I think of the perpetrators of violence, even in cases where I do not identify politically with them, I try to think comprehensively why they did it). Reliability index were for perpetrators $\alpha=.760, .757$ in pre- and post-intervention measures, respectively. An item measured Empathy towards victims (e.g. When I hear the story of people who have suffered from political violence, even in cases where I do not identify politically with them, I try to see the situation from his/ her perspective). Items were rated on a 7-point response scale ranging from $1=$ Not at all to $7=$ Very much.

Emotions. Emotions were measured using the Modified Differential Emotions Scale (mDES, Fredrickson, 2009). Five positive selftranscendent emotions were assessed: Gratitude, Hope, Elevation, LoveTrust, and Serenity-Peace (e.g. During exposure to victims narrative: What is the most inspired, uplifted, or elevated you felt?), along with 4 negative emotions: Anger, Shame, Guilt, and Sadness (e.g. What is the most angry, irritated, or annoyed you felt?), with items rated on a 5 -point response scale ranging from $0=$ Not at all to $4=$ Extremely. Reliability index were $\alpha=.829$ and $\alpha=.629$ respectively. These emotions were measured immediately after the intervention.

Victimisation. An ad-hoc question was created (e.g. Did someone close to you experience political violence: Threatened, Extorted, Exiled, 
Arrested, Imprisoned, Injured, Tortured, Murdered?) coded with $1=$ Yes, $0=$ None.

\subsubsection{DATA ANALYSES}

The statistical analyses were performed using SPSS 22.0 (IBM Corp., 2017). ANOVA tests (i.e. ANCOVAs) were conducted to determine differences among groups, accompanied by respective effect sizes (i.e. $d$ test and eta square for ANOVAs). Mediation analyses were performed to contrast direct and indirect effects of the intervention versus controlinformational condition (a dummy variable was created assigning 0 value to the control condition and a value of 1 to the intervention group) using Hayes' (2013) PROCESS macro for SPSS (v3.3). The bootstrapping estimation method based on 10,000 repetitions was estimated, and all mediator variables were centred (Hayes 2013). The level of significance used was $p \leq .05$. To control for the effect of competitive victimization narratives, victims were grouped into ETA victims and victims of state violence.

\subsection{Results}

\subsubsection{MeANS COMPARISONS BETWEEN GROUPS PRE AND POST INTERVENTION}

Significant interaction effect was found for intergroup forgiveness between control, and two intervention groups $\left(F_{(2,277)}=10.82\right.$, $p<.001, \eta^{2}=.072$ ); effect sizes were $d=0.765$ in Social Work and $d=0.833$ for Teacher Training students, and no significant differences were found for the control group $(d=-0.117)$. ANCOVA analysis revealed higher levels of forgiveness-related attitudes adjusted for pretest measure for the intervention group $(M=4.479, S E=0.090,95 \%$ $\mathrm{Cl}[4.303,4.656])$ compared to control $(M=3.941, S E=0.185,95 \%$ $\mathrm{Cl}[3.576,4.306])$. With respect to the types of victims, all of them produced significant ( $p s>.05$ ) effect sizes, having the narratives of ETA victims a large effect $(d=0.866)$ and Victims of State violence a medium one $(d=0.507)$.

In addition, there were significant statistical differences for personal forgiveness measure. Interaction effect between three groups $\left(F_{(2,277)}=13.46, p<.0001, \eta^{2}=.089\right)$ showed a significant increase in attitudes for interventions groups, Social Work students $d=0.401$ and pre-service teachers students $d=0.255$, by contrast personal forgiveness was decreased in control group $d=-0.464$. The effect 
sizes were similar and low for narratives of ETA victims $d=0.308$ and State violence $d=0.276$.

\subsubsection{EMPATHY TOWARDS PERPETRATORS AND VICTIMS}

We found a significant interaction effect $\left(F_{(2,277)}=3.37, p<.04\right.$ $\left.\eta^{2}=.024\right)$ for Empathy towards perpetrators, with a statistically significant increase in the intervention group of students of Social Work $(d=3,114)$, a lower pre-to-post change among Teacher Training students $(d=0.310)$, and in the control group $(d=0.131)$. ANCOVA analysis revealed higher levels of Empathy towards Perpetrators adjusted for pre-test measure for the intervention group $(M=3.850$, $S E=0.089,95 \% \mathrm{Cl}[3.675,4.026])$ compared to control $(M=3.085$, $S E=0.183,95 \% \mathrm{Cl}[2.724,3.445])$.

In the case of Empathy towards victims, there were a significant interaction effect $\left(F_{(2,277)}=3.96 p<.02, \eta^{2}=.028\right)$, with no preto-post changes for Social Work intervention group $(d=0.003)$ and Pre-Service teachers students $(d=0.025)$, while a decreased level for control group $(d=-0.30)$. Empathy scores towards victims were high at the beginning, with mean scores above 5; therefore, the intervention did not produce a significant increase. In the case of the control group exposed to statistical information, a reverse effect was observed with a slight decrease in Empathy. In contrast, Empathy towards perpetrators was low at baseline (mean scores around 3, on a scale of 1 to 7), and an increase was produced by the intervention, especially in the Social Work students group. Considering the type of victims, there was a significant interaction effect $\left(F_{(1,277)}=3.20\right.$, $\left.p<.04 \eta^{2}=.023\right)$, with the greatest pre-to-post change in the narratives from ETA victims $(d=0.47)$ compared to the victims of State Violence $(d=0.26)$.

\subsubsection{Self-transcendent emotions and negative emotions}

Intervention groups reported higher mean values in STEs compared to those of the control group with a high effect size $\left(F_{(2,279)}=236.25\right.$, $p<.0001, \eta^{2}=.63$ ) (see Figure 1).

Anger and Shame were more intensively reported in the control group than in intervention groups, and the strongest effect was Anger $\left(F_{\text {Anger }(2,277)}=20.18, p<.0001 \eta^{2}=.127 ; F_{\text {Shame }(2,277)}=12.76\right.$, $\left.p<.0001, \eta^{2}=.084\right)$. Conversely, Guilt was higher in the intervention groups $\left(F_{\text {Guilt }(2,277)}=3.08, p<.05, \eta^{2}=.022\right)$ (Figure 2$)$. 
Figure 1

Means of Self-Transcendent Emotions by Conditions

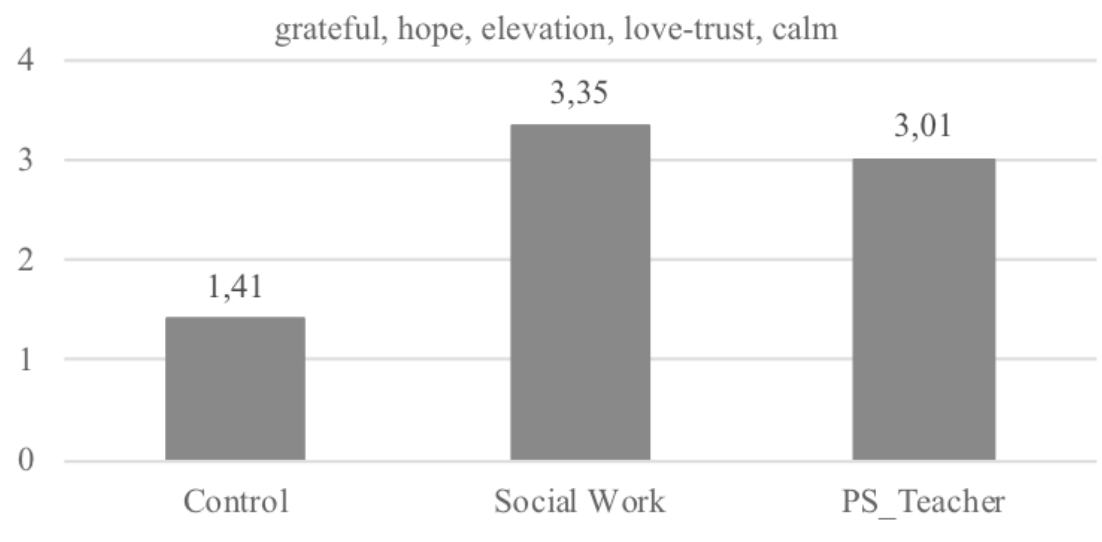

Source: Own elaboration.

Figure 2

Means of negative emotions by conditions

4

3

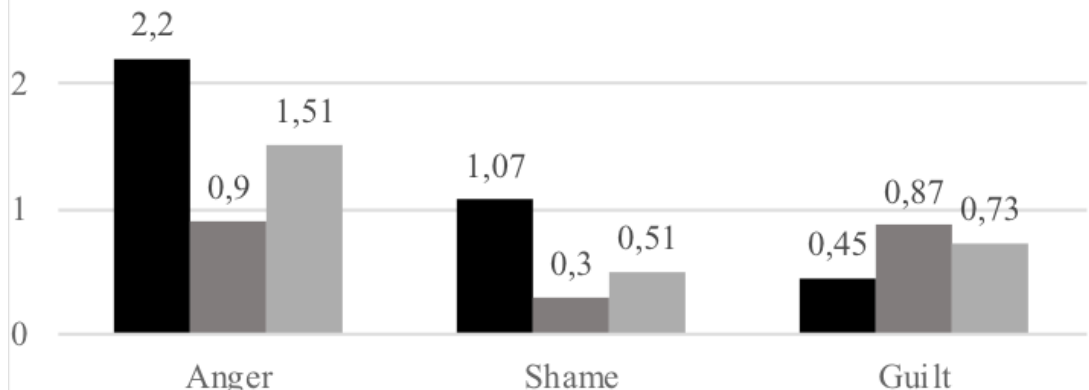

Anger

Shame

Guilt

- Control Social Work $\Perp$ PS_Teacher

Source: Own elaboration.

Deusto Journal of Human Rights

ISSN: 2530-4275 • ISSN-e: 2603-6002, No. 8/2021, 103-130

doi: http://dx.doi.org/10.18543/djhr.2286 • http://djhr.revistas.deusto.es/ 
Figure 3

\section{Mediation effects on intergroup forgiveness through self-transcendent emotions and empathy towards perpetrators}

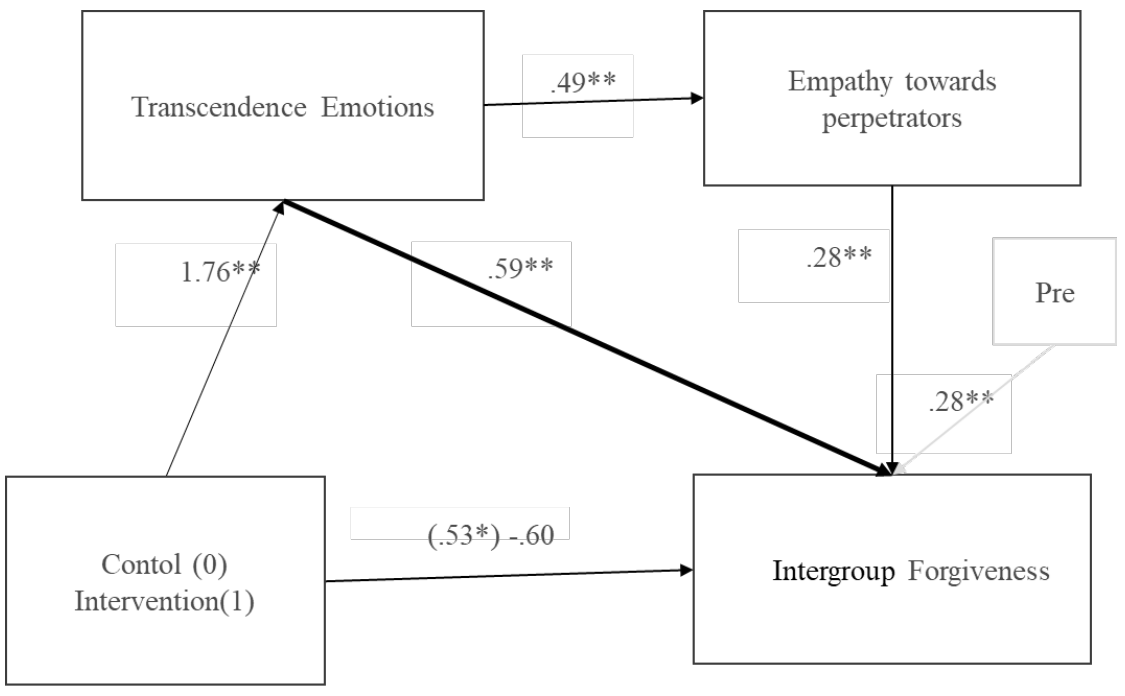

Non standardized regression coefficients are presented. In brackets: total effects $* * \mathrm{p}<.001 ; * \mathrm{p}<.01 ; \mathrm{N}=280$

Group- $>$ TE $>$ IF Indirect effect $\mathrm{B}=.72, \mathrm{SE}=.17 \mathrm{CI}[1.07, .45]$

Group- $>$ TE $>$ EP $>$ IF Indirect effect $\mathrm{B}=.17, \mathrm{SE}=.06 \mathrm{CI}[.30, .06]$

Source: Own elaboration.

\subsubsection{Mediation EFFECTS ON INTERGROUP FORgIVENESS THROUGH SELF-} TRANSCENDENT EMOTIONS AND EMPATHY

Participation in the intervention compared to control, more strongly elicited STEs and Empathy toward perpetrators among participants and both increased intergroup forgiveness, controlling for previous attitudes toward forgiveness. Two indirect statistical significant effects were contrasted: one of them using STEs on forgiveness and the other, through Empathy. The effect of STEs was stronger than that of Empathy (direct and standardized effects were $b=.59$ and indirect .71 and $b=.28$ and indirect $b=.17$, for STEs and Empathy, respectively). The effects of the two mediated variables explained the total effect of the intervention (i.e. full mediation) (see Figure 3). On the other hand, direct and indirect effects on intergroup forgiveness were contrasted 
for empathy towards victims, with a full mediation too, and stronger effects of STEs than Empathy on Intergroup Forgiveness (for STEs, direct standardized effects $b=.65$ and indirect .79; for Empathy, $b=.18$ and indirect $b=.10$ ) (see Figure 4).

Figure 4

Mediation effects on intergroup forgiveness through self-transcendent emotions and empathy towards victims

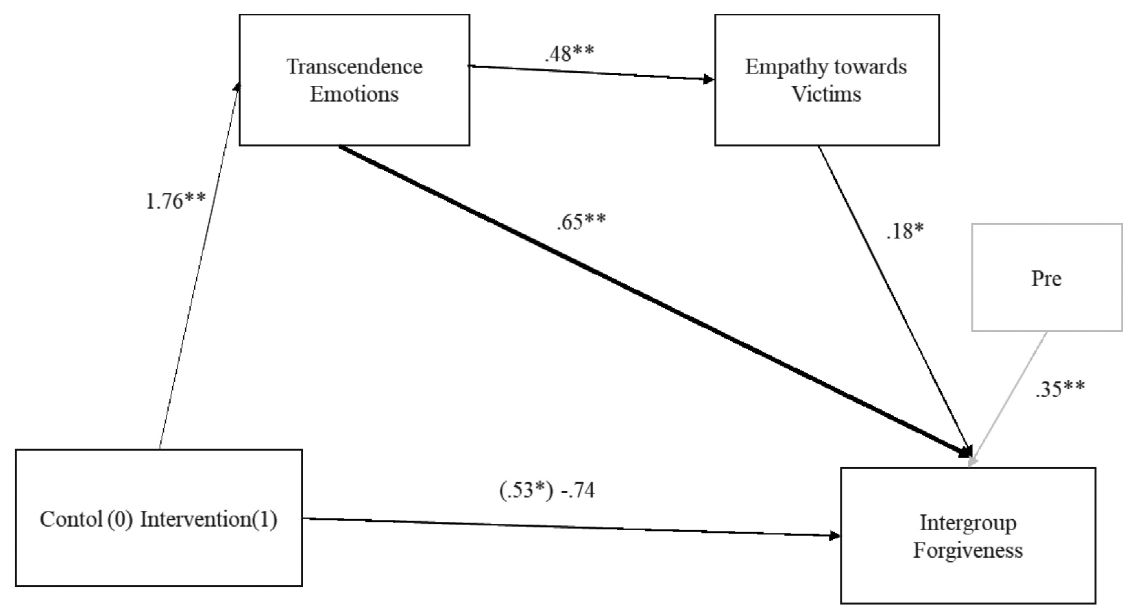

Group $>\mathrm{TE}>\mathrm{IF}$ Indirect effect $\mathrm{B}=.79, \mathrm{SE}=.17 \mathrm{CI}[1.14, .45]$

Group $>$ TE_PEP $\rightarrow$ IF Indirect effect $\mathrm{B}=.10, \mathrm{SE}=.05 \mathrm{CI}[.22, .02]$

Source: Own elaboration.

\subsection{Conclusions}

The Bakeaz Blai intervention based on narratives of victims of violence perpetrated by ETA and State Forces was not only oriented to show victims' experiences, but also to promote peace, forgiveness, and social reconciliation together with breaking competitive victimization. This quasi-experimental design with university students of social sciences showed that, compared to the exposure of statistical data about the conflict, victim's narratives increased favourable attitudes towards forgiveness (i.e. personal and intergroup) among participants $(\mathrm{H} 1)$, and these effects were found controlling for earlier levels pre- 
intervention attitudes. In addition, the intervention effects were not explained to exposure to victimization experiences in participants because the level of victimization was similar in the intervention and control groups.

Of great interest is the fact that the intervention had a stronger effect on intergroup forgiveness than in personal forgiveness -effect sizes were higher in the case of intergroup variable- and people were more favourable to accept a more distal position (e.g. Victims need to forgive the harm that was caused by political violence) than a more personal commitment (e.g. I can forgive actions of those who have caused harm). On the other hand, narratives of ETA victims had a stronger influence compared to those from victims of state violence, an aspect that is considered to be further explored in future studies because only four victims participated in this study.

The intervention had also an impact on empathy towards both victims and perpetrators. However, empathy towards victims was already high before the interventions, while the opposite was true for perpetrators. This may be why the intervention did not succeed at increasing positive attitudes that were held by participants before the intervention. In the case of perpetrators, conversely, the intervention increased empathy towards them. In this sense, it should be highlighted that the empathy measure consisted of a cognitive component to take the perspective of the other person, which is a powerful element that can influence prosocial motivations (Hoffman 1984). In particular, because several studies and meta-analyses have shown notable effects of empathy on interpersonal (e.g. Fehr et al. 2010) and inter-group forgiveness (e.g. Van Tongeren et al. 2014).

Exposition to victims' narrative elicited an emotional experience composed by STEs so that sharing victim's humanizing narratives did inspire behavioural models for forgiveness and cooperation to others, congruently with research about these emotions regarding connection with others (Campos et al. 2013; Van Cappellen and Rimé 2014) and prosocial behaviour (e.g. Haidt 2003; Pizarro et al. 2021; Stellar et al. 2017). These emotions have proven to be the most influential mediating variables in this study.

In relations with negative emotions, exposition to negative and statistical information (i.e. victimization events, with neither an explaining frame nor a humanizing context) provoked higher anger and shame in participants of the control condition, while the intervention participants reported more guilt. Exposition to traumatic and negative events need to be understood to make sense of the experience, and to be shared and discussed: "The more an event provokes an 
emotion, the more it elicits social sharing" (Rimé et al. 2011, 695). This psychological need to make sense of a traumatic experience is not possible when only negative statistical information is received. Under those conditions, people experience especially anger as seen in the present study. On the other hand, guilt (i.e. for the atrocities suffered by others) is conceived as an important predictor of intergroup forgiveness (Van Tongere et al. 2014), although it is depending on the level of categorization. For instance, in the case of the Holocaust when Germans were perceived as outgroup members, victimized group members indicated greater collective guilt and were less willing to forgive contemporary (Wohl and Branscombe 2005).

Complementary, the results showed a strong relationship between STEs and empathy, the latter encompasses other-oriented emotions such as compassion and warmth (Van Tongeren et al. 2014), and STEs (Pizarro et al. 2019). Empathy was positively increased by experiencing emotions during the intervention such as gratitude, hope, elevation, love-trust, or calm, showing that these emotions contribute to perspective-taking and an opening to others views. Supporting hypothesis models proposed and contrasted in this study showed that the participation had a positive effect on intergroup forgiveness through primarily STEs and secondary empathy to victims and also perpetrators $(\mathrm{H} 2)$. In addition, these mediation variables fully explained the relation between the intervention and criterion variable.

\section{Study 2}

This second study analysed a community intervention carried out in the Basque Country. The intervention is denominated "Citizen processes of encounter and dialogue on memory and recognition" (Bakeola 2021). These are group dynamics aimed at volunteers from community organisations and NGOs, having been applied in many groups. However, there is only one systematic evaluation, which is presented in this paper. The general objective is to work on attitudes towards forgiveness and reconciliation and to promote strategies to confront the culture of peace individually and collectively.

The following hypotheses were tested: Participation in peace intervention will be increase attitudes toward intergroup forgiveness and empathy $(\mathrm{H} 1)$, decrease negative outgroup emotions and increase positive outgroup emotions ( $\mathrm{H} 2)$. At the same time, the effect of the intervention on intergroup forgiveness will be mediated through increased outgroup empathy $(\mathrm{H} 3)$. In addition, the change in outgroup 
emotions, with the increase in positive emotions and the decrease in negative emotions, will correlate positively with the increase in intergroup forgiveness.

\subsection{Method}

This is a single-group quasi-experimental design with pre- and posttreatment measures.

\subsubsection{PARTICIPANTS}

The sample was composed of 31 young participants, volunteer members of a social organization of leisure activities for young people $\left(M_{\text {age }}=19.48 S D=3.91,18\right.$ to 37 years old, $75 \%$ women; 25 women and 6 men).

\subsubsection{Procedure}

This intervention was designed by Bakeola (2021), an organization dedicated to peace education. A group of volunteers was invited to evaluate the intervention at the beginning of the program, given the organization's interest in evaluating its results. For this purpose, the participants enrolled at that time were recruited.

The participants were divided randomly into 3 groups. The intervention consisted of 5 sessions (of one and a half hours), applying group dynamics techniques, and distributed as follows:

First session: Framing and approach (presentation of the group). Adjustment of expectations. Explanation of the process and the methodology.

Second session: The past (historical and emotional time spiral). Emotional time spiral where each participant integrates the events that have most affected them, and that has been a turning point.

Third session: The past and the present (violations and consequences of violence). Analysis of the consequences of political violence: Making visible human rights violations and their consequences.

Fourth session: The past and the present (Glencree local; falling off the blindfolds) (based on Glencree experience) (Euskal Telebista 2013). Experiences of positioning in the face of human rights violations.

Fifth session: The present and the future (the drawers and the final evaluation). An imaginative exercise is carried out on what we want to tell the next generations, on what attitudes are necessary. 
The questionnaires were completed before and after each intervention -in the last session. All participants received information about the research project and signed an informed consent form. The data recorded were encoded and anonymized to ensure anonymity.

\subsubsection{MeAsures}

Forgiveness. The same scale was applied as in study 1 (see above). Intergroup reliability index were $\alpha=.871, .856$ pre and post measures, and for personal forgiveness $\alpha=.871, .856$ pre and post respectively.

Intergroup empathy. The same scale was applied as in study 1 (see above). Empathy towards perpetrators and victims were composed of two items respectively, and the reliability index was $\alpha=.884 / 663$, $.882 / 893$ pre and post Perpetrators empathy and victims, respectively.

Intergroup emotions. A scale about emotions experienced toward outgroup was applied (ad hoc) (e.g. To what extent do you experience the following feelings towards people who think radically differently than you on this subject: anger, hate, respect and empathy).

Processual variable: quality of the Participation (Zumeta et al. 2016). Participants answered satisfaction with participation in the intervention (1 item).

All scales applied ranged from 1 (not at all) to 7 (very much).

\subsection{Results}

Comparing pre- and post-intervention measures in criterion variables, intergroup forgiveness was increased after the intervention $\left(M=3.55, S D=1.37, M=4.27, S D=1.71 ; F_{(1,30)}=7.786, p<.01\right.$, $\left.\eta^{2}=.21\right)$. Nevertheless, no statistical significant differences were found on personal forgiveness $\left(F_{(1,30)}=0.813, p<.374\right)$. Empathy, on the other side, increased in both variables; in Empathy towards perpetrators $\left(M=3.75, S D=1.68, M=5.05, S D=1.37 ; F_{(1,30)}=17.518, p<.0001\right.$, $\left.\eta^{2}=.37\right)$ and towards victims $(M=4.98, ' S D=1.52, M=5.58$, $\left.S D=1.29 ; F_{(1,30)}=7.02, p<.013, \eta^{2}=.19\right)$.

With regard to intergroup emotions towards people who think radically differently than oneself, we found decreased levels in Anger $\left(M=4.65, S D=1.85, M=3.48, S D=1.76 ; F_{(1,30)}=17.86, p<.001\right.$, $\left.\eta^{2}=.37\right)$ and Hate $(M=3.65, S D=2.18, M=2.94, S D=1.75$, $\left.F_{(1,30)}=8.30, p<.007, \eta^{2}=.22\right)$, and increased levels in Respect $\left(M=4.10, S D=1.92, M=5.16, S D=1.63 ; F_{(1,30)}=13.53, p<.001\right.$, 
$\left.\eta^{2}=.31\right)$ and Empathy $(M=3.23, S D=1.60, M=4.55, S D=1.67$; $\left.F_{(1,30)}=13.03, p<.001, \eta^{2}=.30\right)$ after the intervention.

A mediational model was tested using outgroup Empathy as a mediator variable in the relation between quality of the participation (i.e. satisfaction) and intergroup forgiveness. No significant effects were found (all $p>$.05). In detail, the direct effect of satisfaction with participation on forgiveness was $B=.238$ (SE $=.241, p=.33,95 \% \mathrm{Cl}$ $[-0.172,0.649])$, and the indirect effect through empathy towards victims was $B=.025(S E=.113,95 \% \mathrm{Cl}[-0.137,0.213])$ and toward perpetrators was $B=.021$ (SE $=.118,95 \% \mathrm{Cl}[-0.136,0.231]$ ).

Two indexes for change in outgroup emotions were created, resulting from the differences between post- and pre-intervention measures of negative (i.e. Anger and Hate) and positive (i.e. Respect and Empathy) emotions. Correlations coefficients between outgroup emotions and intergroup forgiveness and empathy at post-intervention were all statistical significant. Particularly, positive and negative outgroup emotions correlated with intergroup $\left(r_{(31)}=.54, p<.002\right.$, and $r_{(31)}=-.41, p<.02$, respectively) and personal forgiveness $\left(r_{(31)}=.71\right.$, $p<.0001$, and $r_{(31)}=-.45, p<.02$, respectively), and with Empathy towards perpetrators $\left(r_{(31)}=.58, p<.001\right.$, and $r_{(31)}=-.56, p<.001$, respectively) and victims $\left(r_{(31)}=.61, p<.0001\right.$, and $r_{(31)}=-.64$, $p<.0001$, respectively).

Subsequently, partial correlations were estimated, showing that the increase in positive outgroup emotions (i.e. Respect and Empathy) correlated positively with Empathy towards victims controlling for the previous score on empathy $\left(r_{(28)}=.42, p<.02\right)$. The partial correlation between decreased negative outgroup emotions and Empathy towards victims was marginally statistically significant $\left(r_{(28)}=-.30, p<.10\right)$. Concerning Empathy toward perpetrators, and for outgroup forgiveness partial correlations were not statistically significant ( $p s>.10)$.

\subsection{Conclusions}

A community intervention was carried out in the Basque Country, with a program created and implemented in various groups of voluntary people from Non-Governmental Organizations and public institutions (Bakeola 2021). Nevertheless, no systematic evaluation of peace attitudinal variables has been evaluated and published. This work is therefore the first systematic evaluation to be carried out to date.

The intervention was based on a programme of sessions in which the involvement of the participants was encouraged. It started by 
adjusting expectations in the initial sessions, integrating personal experiences, reviewing the traumatic events experienced and making visible the collective violence experienced by all victims. In addition, it had as a central principle the analysis regarding human rights violations and ended with the commitment to the construction of collective memory and its intergenerational transmission.

The results have shown, as in the previous study (see study 1), that the group intervention helps to change attitudes, and particularly, it can promote intergroup attitudes that favour perspective-taking and empathy, as well as intergroup forgiveness $(\mathrm{H} 1)$. The intervention provoked an increase in empathy towards victims, which was already high before the intervention. Perspective-taking towards perpetrators was low at the beginning and increases slightly after the intervention. Attitudes in favour of intergroup forgiveness also changed with the intervention, although attitudes towards personal forgiveness did not change. This suggests that, after being exposed to narratives depicting victimisation and the need for social reconciliation, it is more difficult to assume forgiveness for oneself than for others in general. Further, we did not find support for the mediation model according to which the effect of the quality of the intervention on intergroup forgiveness would have been mediated through increased outgroup empathy.

On the other hand, a significant change was observed after the intervention in intergroup emotions, with an increase in empathy and respect for groups that hold another point of view, and a decrease in intense negative emotions such as anger and hate $(\mathrm{H} 2)$. It was also found that the change in intergroup emotions was associated with intergroup forgiveness and empathy, suggesting that a change in intergroup emotions may improve intergroup relations, understanding of other viewpoints and the search for a peaceful solution that allows for intergroup forgiveness.

However, the data did not support the mediation model hypothesis or demonstrate that change in intergroup variables is a predictor of intergroup forgiveness $(\mathrm{H} 3)$. Finally, it has to be mentioned that the design employed has important limitations, one of them being the small sample size of 31 participants, which affects statistical power. In addition, the applied design is a single-group design, which does not allow for causal inference. Future research that expands the sample size and increases rigorous assessments of the intervening variables may improve and refine these results. 


\section{Discussion}

This research explored the impact of victims' narratives about the traumatic impact of political violence in the Basque country, being the first attempt at systematically evaluating the possible benefits of these programs. While the construction of a common collective memory of the violent past through inclusive memories are needed to promote more positive intergroup relations in the present, excessive memory of suffering can have ambivalent consequences for intergroup relations, endangering coexistence (Bobowik et al. 2014). Collective narratives that emphasize ingroup suffering, collective victimhood and revenge, may fuel the conflict (Páez and Liu 2012). On the contrary, if collective narratives are framed on shared suffering and mutual forgiveness for the harm — such as those presented in these studies-, they can facilitate peaceful coexistence (Salomon 2004; Vollhardt 2015).

As research has shown, perspective-taking and/or empathic emotions among conflicting parties or groups and their divergent perceptions are a strong predictor of intergroup forgiveness (Noor et al. 2008, 2015; Van Tongeren et al. 2014). Also, reducing the intense negative emotions between groups will facilitate social sharing and dialogue (Tam et al. 2007; Wohl and Branscombe 2005; Wohl et al. 2012). However, as observed in the Truth and Reconciliation Gacaca trials after the genocide in Rwanda, the psychosocial impact was ambivalent, so participation in rituals enhanced social the social cohesion of both victim and prisoner participants, but also a confrontation with perpetrators triggered reliving past traumas, and renew feelings of sadness, anger and fear (Staub 2012). These results highlight that the effects of transitional justice rituals are not equivalent to the societal and individual level, and for victims and perpetrators.

This research had the objective of advancing in the systematic evaluation of intervention programs in a culture of peace in Postconflict Settings (Basque country), based on contact and dialogue, and through testimonies in a supportive context -i.e. preparing participants to active listening to educators victim's narratives, empathizing with the other, taking the other's perspective, sharing emotions and suffering, and humanizing the other (Staub 2012). The social sharing dialogue with educational victims enhance an experience of common humanity, self-transcendent emotions (e.g. awe, inspiration, gratitude, compassion, or feeling moved by love), inspire moral models and inclusive caring, and thus promote prosocial tendencies (empathy and intergroup forgiveness). 
Both interventions proposed here (Educational programme: Bakeaz Blai and Citizen processes of encounter and dialogue on memory and recognition) have proven positive effects in participants. They increased forgiveness, but more intergroup (large effect sizes) than interpersonal forgiveness (medium or low effect sizes), as well as empathy, in line with others studies on intergroup forgiveness (e.g. Van Tongeren et al. 2014). In the case of educator victims, STEs arising from the contact with victims narratives promote prosocial tendencies (empathy and intergroup forgiveness) through mediational effects. However, there was no effect in the case of the second intervention and it is thought that limitations related to the design, the absence of a comparison control group and small sample size could account for the absence of this finding. In the case of the second intervention, a change in outgroup emotions was achieved, with greater respect and empathy and less anger and hate towards the outgroup and divergent views on the conflict.

On the other hand, the condition based exclusively on statistical information about victimization provoked higher levels of anger and shame and lower guilt than in the intervention condition. This highlights the motivational need to understand traumatic events and to make sense of the experience, and socially share emotional experiences (Rimé et al. 2011). These results centre the attention on the discussion of the effects of the information transmitted in the mass media and through social networks, in which terrorist attacks - and other forms of political violence- are presented without contextualising the facts, without humanising, or giving meaning to the atrocities presented.

There are several international experiences around community initiatives to confront the violent past (e.g. López López and Taylor 2021). The intergroup reparation rituals have demonstrated ambivalent effects on victims, with an increase in negative emotions during and after rituals participation, as well as a positive effect such as empowering communities in Guatemala (Martín-Beristain et al. 2010b) or reducing negative outgroup stereotypes in Rwanda (Rimé et al. 2011). Meta-analytical evidence showed that intergroup forgiveness was associated with intergroup contact, empathy and an inclusive identity that breaks down boundaries between groups (Van Tongeren et al. 2014). Nevertheless, there is not abundant evidence supporting the effects of active victim's participation in community settings. In this sense, this study is an innovative proposal that evidences the moral role of victim's educators. Its commitment to the transmission to younger generations of the violent past, and at the same time to the education of young people to peaceful coexistence. 
Complementary, the results also highlight a dynamic intervention based on a confrontation to victimization and perspective-taking (outgroup empathy) based on an exposition and analysis of the several narratives victims ("Gleencre" was the first meeting between victims of the different groups of perpetrators in the Basque Country who wanted to share their experiences of victimization). Both narratives incorporate learning and psychological growth, which accompanies the suffering of remembering a sense of justice and reparation. At this moment and more than 10 years after the cessation of ETA violence, there is a strong public debate in Spain and the Basque Country about the recognition of all victims (of ETA as well as of police forces). We believe that these community proposals can support the community psychosocial work in favour of the culture of peace and the recognition of the damage caused. We hope that these results confirm the importance of a) the implementation of peace and coexistence community interventions, b) their evaluation with scientific methods that can prove their validity, and c) the promotion of emotional and moral examples and the relevance of outgroup empathy, as mechanisms to promote peaceful attitudes in post-conflict societies. All of this, in the context of the transmission of traumatic narratives of collective violence to younger generations. Finally, the need for further research on prevention and reconciliation interventions in post-conflict settings is emphasised and called for.

\section{References}

Bakeola. 2021. Procesos ciudadanos. Accessed September 10, 2021. http:// www.bakeola.org/procesosciudadanos/index.html

Bobowik, Magdalena, M. Ángeles Bilbao, and Joana Momoitio. 2010. "Psychosocial effects of forgiveness petition and "self-criticism" by the Basque Government and Parliament directed to the victims of collective violence.» Journal of Social Psychology 25, no. 1: 87-100. https://doi. org/10.1174/021347410790193478.

Bobowik, Magadalena, Miren Harizmendi, Nekane Basabe, Saioa Telletxea, and José J. Pizarro. 2018. Bakeaz Blai: Social Sharing of the Victims' Narrations Towards Reconciliation and Forgiveness Attitudes. Workshop on: «Sharing and Regulating Emotions in Legal Spaces: Mediation, Restoration, and Reconciliation.» Oñati: Oñati International Institute for the Sociology of Law: 31 May-1 June.

Bobowik, Magdalena, Darío Páez, James H. Liu, Laurent Licata, Olivier Klein, and Nekane Basabe. 2014. "Victorious justifications and criticism of defeated: Involvement of nations in World Wars, social development, 
cultural values, social representations of war, and willingness to fight.» International Journal of Intercultural Relations 43: 60-73. https://doi. org/10.1016/j.jijintrel.2014.08.013.

Bobowik, Magadalena, Dario Páez, Patrycja Slawuta, and Nekane Basabe. 2019. "How framing past political violence affects reconciliation through responsibility attributions and ingroup victimhood: the Basque case.» The International Journal of Restorative Justice 2, no. 2: 235-259. https://doi. org/10.5553/JJRJ/258908912019002002004.

Campos, Belinda, Michelle N. Shiota, Dacher Keltner, Gian C. Gonzaga and Jennifer L. Goetz. 2013. "What is shared, what is different? Core relational themes and expressive displays of eight positive emotions.» Cognition and Emotion 27, no. 1: 37-52. https://doi.org/10.1080/026999 31.2012.683852.

Carmena, Manuela, Jon M. Landa, Ramón Múgica, y Juan Mª Uriarte. 2013. Informe-base de vulneraciones de derechos humanos en el caso vasco (1960-2013). Vitoria-Gasteiz: Secretaría general de paz y convivencia, Gobierno Vasco. Accessed September 10, 2021. https://www.euskadi.eus/ documentos-paz-convivencia/web01-s1lehbak/es/.

Euskal Telebista. 2013. Glencree. Víctimas y memoria. Accessed September 10, 2021. https://www.eitb.tv/es/video/terror-de-estado-en-el-pais-vascoterror-de-estado-en-el-pais-vasco/6249/49310/glencree

Fehr, Ryan, Michele J. Gelfand, and Monisha Nag. 2010. "The road to forgiveness: a meta-analytic synthesis of its situational and dispositional correlates.»Psychological bulletin 136, no. 5: 894-914. https://doi. org/10.1037/a0023012.

Fredrickson, Barbara L. 2009. Positivity. New York: Publisher Three Rivers Press.

Gibson, James L. 2004. Overcoming Apartheid: Can Truth Reconcile a Divided Nation? New York: Russell Sage Foundation.

Gobierno de España. 2011. Víctimas de ETA. Ministerio del Interior. Accessed June 1, 2021. http://www.mir.es/DGRIS/Terrorismo_de_ETA/ultimas_ victimas/p12b-esp.htm.

Gobierno Vasco. 2021a. Víctimas: verdad, justicia y reparación. Accessed September 10, 2021. https://www.euskadi.eus/victimas-verdad-justicia-yreparacion/web01-s1lehbak/es/

Gobierno Vasco. 2021b. Derechos Humanos, Convivencia y Cooperación. Accessed September 10, 2021. https://www.euskadi.eus/modulo-adiadian/web01-s1lehbak/es/

Haidt, Jonathan 2003. "The moral emotions.» In Handbook of affective sciences, edited by Davidson, Richard J., Klaus R. Sherer, and H. Hill Goldsmith, 852-870, Oxford: Oxford University Press. Accesses September 10, 2021. https://www.overcominghateportal.org/ uploads/5/4/1/5/5415260/the_moral_emotions.pdf

Hayes, Andrew F. 2013. Methodology in the social sciences. Introduction to mediation, moderation, and conditional process analysis: A regressionbased approach. New York: Publisher Guilford Press. 
Hoffman, Martin L. 1984. "Interaction of affect and cognition in empathy.» In Emotions, Cognition, and Behavior, edited by Carroll E. Izard, Jerome Kagan, and \& Robert B. Zajonc, 103-131, New York: Cambridge University Press.

Krug, Etienne G, James A. Mercy, Linda L. Dahlberg, and Anthony B. Zwi. 2002. "The World report on violence and health.» The Lancet 360, October 5: 1083-1088. https://doi.org/10.1016/S0140-6736(02)11133-0.

Larizgoitia, Itziar, Itziar Fernández, Iñaki Markez, Isabel Izarzugaza, Arantza Larizgoitia, Florentino Moreno, Dario Páez, and Carlos Martin Beristain. 2011a. "Secuelas de la violencia colectiva: hablan las víctimas del estudio ISAVIC.» Gaceta Sanitaria 25, no 2: 115-121. https://doi.org/10.1016/j. gaceta.2010.11.005.

Larizgoitia, Itziar, Isabel Izarzugaza, loseba Iraurgi, Javier Ballesteros, Carlos G. Forero, Iñaki Márquez, and Jordi Alonso. 2011b. «Impacto de la violencia colectiva en la salud. Resultados del estudio ISAVIC en el País Vasco.» Gaceta sanitaria 25, no 2: 108-114. https://doi.org/10.1016/j. gaceta.2010.09.019.

Lastrego, Simona, and Laurent Licata. 2010. "Should a country's leaders apologize for its past misdeeds?' An analysis of the effects of both public apologies from a Belgian official and perception of Congolese victims' continued suffering.» Journal of Social Psychology 25 no 1, 61-72. https:// doi.org/10.1174/021347410790193432.

López López Wilson and Laura K. Taylor (eds.) 2021. Transitioning to Peace: Promoting Global Social Justice and Non-violence.Springer: Cham.

Martín Beristain, Carlos, and Darío Páez. 2000. Violencia, apoyo a las víctimas y reconstrucción social. Experiencias internacionales y el desafío vasco. Madrid: Fundamentos.

Martín-Beristain, Carlos, Dario Páez, Bernard Rimé, and Patric Kanyangara. 2010a. "Psychosocial effects of participation in rituals of transitional justice: A collective-level analysis and review of the literature of the effects of TRCs and trials on human rights violations in Latin America.» Journal of Social Psychology 25, no 1: 47-60. https://doi. org/10.1174/021347410790193450.

Martín-Beristain, Carlos, Dario Páez, Bernard Rimé, and Patrick Kanyangara. 2010b. «Efectos psicosociales de la participación en rituales de justicia transicional.» Revista de Psicología, 28, no 1: 9-35. https://doi. org/10.18800/psico.201001.001.

Mullet, Etienne, Maria da Conceição Pinto, Stéphanie Nann, Joachim Kadima Kadiangandu, and Félix Neto. 2011. "Hacia una política positiva: el caso del perdón en el contexto intergrupal en Asia y África.» In Superando la Violencia Colectiva y Construyendo Cultura de Paz, edited by Dario Páez, Carlos Martin-Beristain, José Luis González, Nekane Basabe, and Joseph de Rivera, 377-398, Madrid: Fundamentos.

Noor, Masi, Rupert Brown, Roberto Gonzalez, Jorge Manzi, and Christopher Alan Lewis. 2008. "On positive psychological outcomes: What helps groups with a history of conflict to forgive and reconcile with each 
other?.»Personality and Social Psychology Bulletin 34, no. 6: 819-32. https://doi.org/10.1177/0146167208315555.

Noor, Masi, Nurit Shnabel, Samer Halabi, and Bertjan Doosje. 2015. «Peace vision and its socio-emotional antecedents: The role of forgiveness, trust, and inclusive victim perceptions.» Group Processes \& Intergroup Relations 18, no. 5: 644-54. https://doi.org/10.1177/1368430215586604.

Páez, Dario. 2010. "Official or political apologies and improvement of intergroup relations: A neo-Durkheimian approach to official apologies as rituals.» Journal of Social Psychology 25 no. 1: 101-115. https://doi. org/10.1174/021347410790193504.

Páez, Dario. \& James H. Liu. 2012. "Collective Remembering». In The Encyclopedia of Peace Psychology, edited by D. J. Christie, 155-159, Oxford: Blackwell.

Páez, Darío, Carlos Martin-Beristain, José Luis González, Nekane Basabe, and Joseph de Rivera. 2011. Superando la Violencia Colectiva y Construyendo Cultura de Paz. Madrid: Fundamentos.

Pizarro, José J., Nekane Basabe, Alberto Amutio, Saioa Telletxea, Miren Harizmendi, and William Van Gordon. 1019. "The mediating role of shared flow and perceived emotional synchrony on compassion for others in a mindful-dancing program.» Mindfulness 11, no. 1: 125-39. https:// doi.org/10.1007/s12671-019-01200-z.

Pizarro, José J., Nekane Basabe, Itziar Fernández, Pilar Carrera, Pedro Apodaca, Carlos I. Man Ging, Olaia Cusi and Darío Páez. 2021. «Self-Transcendent emotions and their social effects: Awe, elevation and kama muta promote a human identification and motivations to help others.» Frontiers in Psychology 12: 1-17. https://doi.org/10.3389/fpsyg.2021.709859.

Rimé, Bernard, Patrick Kanyangara, Vincent Yzerbyt, and Dario Paez. 2011. «The impact of Gacaca Tribunals in Rwanda: Psychosocial effects of participation in a truth and reconciliation process after a genocide.» European Journal of Social Psychology 41, no. 6: 695-706. https://doi.org/10.1002/ejsp.822.

Ruiz, Gorka, y Rocío Salazar. 2014. «Bakeaz Blai: Programa pedagógico con víctimas educadoras.» Oñati Socio-legal Series [online] 4 no. 3: 525-549. Accessed September 10, 2021. http://ssrn.com/abstract=2368140.

Salomon, Gavriel. 2004. "A narrative-based view of coexistence education.» Journal of Social Issues 60: 273-288. https://doi.org/10.1111/j.00224537.2004.00118.x.

Shnabel, Nurit, Samer Halabi, and Masi Noor. 2013. «Overcoming competitive victimhood and facilitating forgiveness through re-categorization into a common victim or perpetrator identity.» Journal of Experimental Social Psychology 49 no. 5: 867-877. https://doi.org/10.1016/j.jesp.2013.04.007.

Staub, Ervin. 2012. "Genocide, mass killing, and violent conflict: Prevention.» In The Oxford Handbook of Intergroup Conflict, edited by Linda R. Tropp, 273-290, Oxford: Oxford University Press. https://doi.org/10.1093/oxfordh b/9780199747672.013.0016.

Staub, Ervin, and Lorin A. Pearlman. 2001. "Healing, reconciliation, and forgiving after genocide and other collective violence.» In Forgiveness and 
reconciliation, edited by Raymond G. Helmick and Rodney L. Petersen, 195-217, Radnor, PA: Templeton Foundation Press.

Stellar, Jennifer E., Amie M. Gordon, Paul K. Piff, Daniel Cordaro, Craig L. Anderson, Yang Bai, Laura A. Maruskin, and Dacher Keltner. 2017. "Selftranscendent emotions and their social functions: Compassion, gratitude, and awe bind us to others through prosociality.» Emotion Review 9, no. 3: 200-207. https://doi.org/10.1177/1754073916684557.

Tam, Tania, Miles Hewstone, Ed Cairns, Nicole Tausch, Greg Maio, and Jared Kenworthy. 2007. "The impact of intergroup emotions on forgiveness in Northern Ireland.» Group Processes \& Intergroup Relations 10, no. 1: 119-36. https://doi.org/10.1177/1368430207071345.

Van Cappellen, Patty, and Bernard Rimé. 2014. "Positive emotions and selftranscendence.» In Religion, personality, and social behaviour, edited by Vassilis Saroglou, 123-145. New York: Psychology Press. https://doi. org/10.4324/9780203125359.

Van Tongeren, Daryl R., Jeni L. Burnette, Ernest O'Boyle, Everett L. Worthington, and Donelson R. Forsyth. 2014. "A meta-analysis of intergroup forgiveness.» The Journal of Positive Psychology 9, no. 1: 81-95. https://doi.org/10.1080/17439760.2013.844268.

Wohl, Michael J., Matthew J. Hornsey, and Shannon H. Bennett. 2012. "Why group apologies succeed and fail: Intergroup forgiveness and the role of primary and secondary emotions.» Journal of Personality and Social Psychology 102, no. 2: 306-22. https://doi.org/10.1037/a0024838.

Wohl, Michael J., and Nyla R. Branscombe. 2005. «Forgiveness and collective guilt assignment to historical perpetrator groups depend on level of social category inclusiveness.» Journal of Personality and Social Psychology 88, no. 2: 288-303. https://doi.org/10.1037/0022-3514.88.2.288.

Vollhardt, Johanna Ray. 2015. "Inclusive victim consciousness in advocacy, social movements, and intergroup relations: promises and pitfalls.» Social Issues and Policy Review 9, no. 1: 89-120. https://doi.org/10.1111/ sipr.12011.

Zumeta, Larraitz, Nekane Basabe, Anna Wlodarczyk, Magdalena Bobowik, and Dario Páez, D. 2016. "Shared flow and positive collective gatherings.» Annals of Psychology 32, no. 3: 717-727. http://dx.doi.org/10.6018/ analesps.32.3.261651. 


\section{Copyright}

Deusto Journal of Human Rights / Revista Deusto de Derechos Humanos is an Open Access journal; which means that it is free for full and immediate access, reading, search, download, distribution, and reuse in any medium only for non-commercial purposes and in accordance with any applicable copyright legislation, without prior permission from the copyright holder (University of Deusto) or the author; provided the original work and publication source are properly cited (Issue number, year, pages and DOI if applicable) and any changes to the original are clearly indicated. Any other use of its content in any medium or format, now known or developed in the future, requires prior written permission of the copyright holder.

\section{Derechos de autoría}

Deusto Journal of Human Rights / Revista Deusto de Derechos Humanos es una revista de Acceso Abierto; lo que significa que es de libre acceso en su integridad inmediatamente después de la publicación de cada número. Se permite su lectura, la búsqueda, descarga, distribución y reutilización en cualquier tipo de soporte sólo para fines no comerciales y según lo previsto por la ley; sin la previa autorización de la Editorial (Universidad de Deusto) o la persona autora, siempre que la obra original sea debidamente citada (número, año, páginas y DOI si procede) y cualquier cambio en el original esté claramente indicado. Cualquier otro uso de su contenido en cualquier medio o formato, ahora conocido o desarrollado en el futuro, requiere el permiso previo por escrito de la persona titular de los derechos de autoría. 